\title{
Spatial analysis of landslide susceptibility using failure rate approach in the Hindu Kush region, Pakistan
}

\author{
Ghani Rahman ${ }^{1, *}$, Atta-ur Rahman ${ }^{2}$, Sami Ullah ${ }^{2}$, \\ Muhammad Miandad ${ }^{1}$ and Andrew E Collins ${ }^{3}$ \\ ${ }^{1}$ Department of Geography, University of Gujrat, Gujrat, Pakistan. \\ ${ }^{2}$ Department of Geography, University of Peshawar, Peshawar 25120, Pakistan. \\ ${ }^{3}$ Disaster and Development Network, Department of Geography and Environmental Sciences, \\ Northumbria University, Newcastle, UK. \\ *Corresponding author.e-mail: ghanigeo@gmail.com
}

MS received 14 November 2017; revised 1 May 2018; accepted 31 May 2018; published online 25 February 2019

This paper analyses and applies a spatio-statistical failure rate (SSFR) technique for landslide susceptibility zonation in the Hindu Kush region, Pakistan. The study area (Shahpur valley) is located in the eastern Hindu Kush mountain system. In Shahpur valley, land sliding is a recurrent and costly extreme event. Geologically, this region constitutes the youngest mountain systems and almost every year landslide-induced losses are reported. The frequency and intensity of landslide events is expected to further increase in future due to rapid population growth over the fragile slopes, infrastructural development and deforestation. In order to achieve objectives of the study, data were obtained from both primary and secondary sources. In Shahpur valley, an inventory of the past 300 landslide events of various sizes has been identified and marked on a SPOT satellite image of $2.5 \mathrm{~m}$ resolution. In order to identify the influence of landslide triggering factors, such as geology, tectonic structures, land use, slope angle, slope aspect, roads and streams, a univariate SSFR technique has been tested and applied for calculating the susceptibility score in each class of the selected parameters. Based on factor maps and cumulative score, the landslide susceptibility zones have been developed and validated appearing to be significantly reflecting the pattern of the past landslide events.

Keywords. Landslide; susceptibility; failure rate; factor map; susceptibility score.

\section{Introduction}

Landslides, floods, earthquakes and glacial lake outburst floods are frequently occurring extreme events in the Hindu Kush-Himalayan (HKH) region (Rahman and Shaw 2014). In the HKH region, landslide is a recurring disaster, in terms of occurrence, extent of damage and human casualties (Rahman et al. 2014). However, individual slide may not be as devastating as flood and earthquake (Farooq 1997; Mirnazari and Ahmad 2013).
The objectives of this study were to develop the inventory of past landslide events, explore the major causative factors of landslide occurrences and to prepare landslide susceptibility zonation (LSZ) map using the spatio-statistical failure rate (SSFR) method. Worldwide, amongst all the environmental disasters that occurred during 19902005 , the proportion of landslides is $5 \%$ (Kanungo et al. 2009), being expected to increase further due to unprecedented human intervention over the fragile slopes, seismic activities and increasing intensity 
of regional precipitation under changing climate scenario (Pareek et al. 2010; Conforti et al. 2014).

Landsliding is a complex geomorphic process determined by the interaction of both internal and external factors (Allen et al. 2011). Landsliding in a region depends on several inter-disciplinary factors (Nandi and Shakoor 2010). The slope stability is governed by the rock-mass strength and largely depends on factors namely slope gradient, surface geology, seismic activity, drainage pattern and land cover that influence an area to be susceptible to the landslide phenomenon (SudmeierRieux et al. 2012). It is evident that landslide occurrences increase with increase in slope angle (Rahman et al. 2011). Likewise, slope aspect has a close relationship with landslide incidences as slope aspect indirectly influences precipitation, vegetation cover and soil thickness over a slope (Sengupta et al. 2010). The frequency of landslide events is greater particularly in the region with heavy precipitation. Lithology is another landslide susceptibility factor affecting slope stability (Van Westen et al. 2010; Rahman et al. 2011). Globally, many disastrous landslides have also been initiated by seismic activities and same is the case in the HKH region (Kamp et al. 2010). In the study

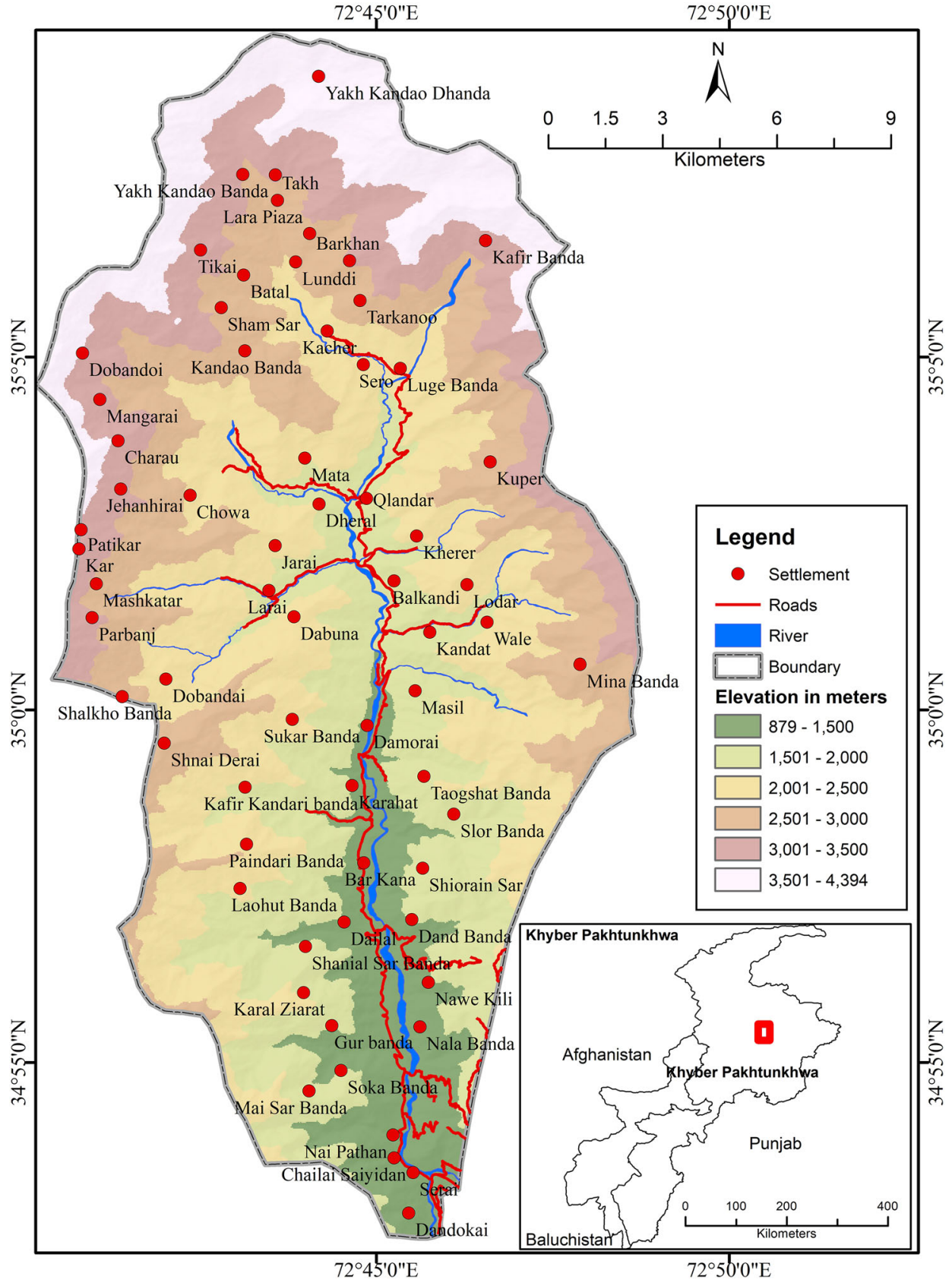

Figure 1. Shahpur valley, digital elevation map. 
area, rapid pace of population growth has further aggravated landslide susceptibility. In the Hindu Kush region, extensive human intervention in the form of road construction, settlement expansion and deforestation have also contributed much to the slope instability.

Scientists have used qualitative, semiquantitative and quantitative approaches to assess landslide susceptibility (Van Westen et al. 2008). Qualitative methods have used a landslide index to identify areas with similar geological and geomorphological characteristics that are susceptible to landslides (Kouli et al. 2010). A semi-quantitative method can be based on some qualitative methodologies, which uses weighting and rating procedures and local knowledge (Ayalew and Yamagishi 2005). However, a quantitative technique uses pure mathematical expression of correlation between causal factors and landslides. The quantitative approaches are based on assumptions and favor the analogy that factors of past landslide incidences will have a higher potential to trigger landslides in the future. In this regard, future spatial probability of landslides is determined by using certain statistical approaches vis-à-vis frequency ratio, information value, SSFR, weight of evidence, analytical hierarchy process and logistic regression. The predictive probability of quantitative approaches relies on inventory of past landslides and thematic maps of landslide causative factors (Hussin et al. 2016). In recent years, the use of geospatial technology is widely applied for landslide susceptibility assessment, risk identification and management (Akbar and $\mathrm{Ha}$ 2011).

Geospatial technology provides a framework for mapping the past landslide events and combines the landslide causative factors for producing landslide susceptible maps and therefore it becomes an integral part of LSZ studies. SSFR method is more beneficial compared to other methods in the sense that it takes into consideration the underlying factors that cause landslides in the $\mathrm{HKH}$ region. Data about parameters used in this method

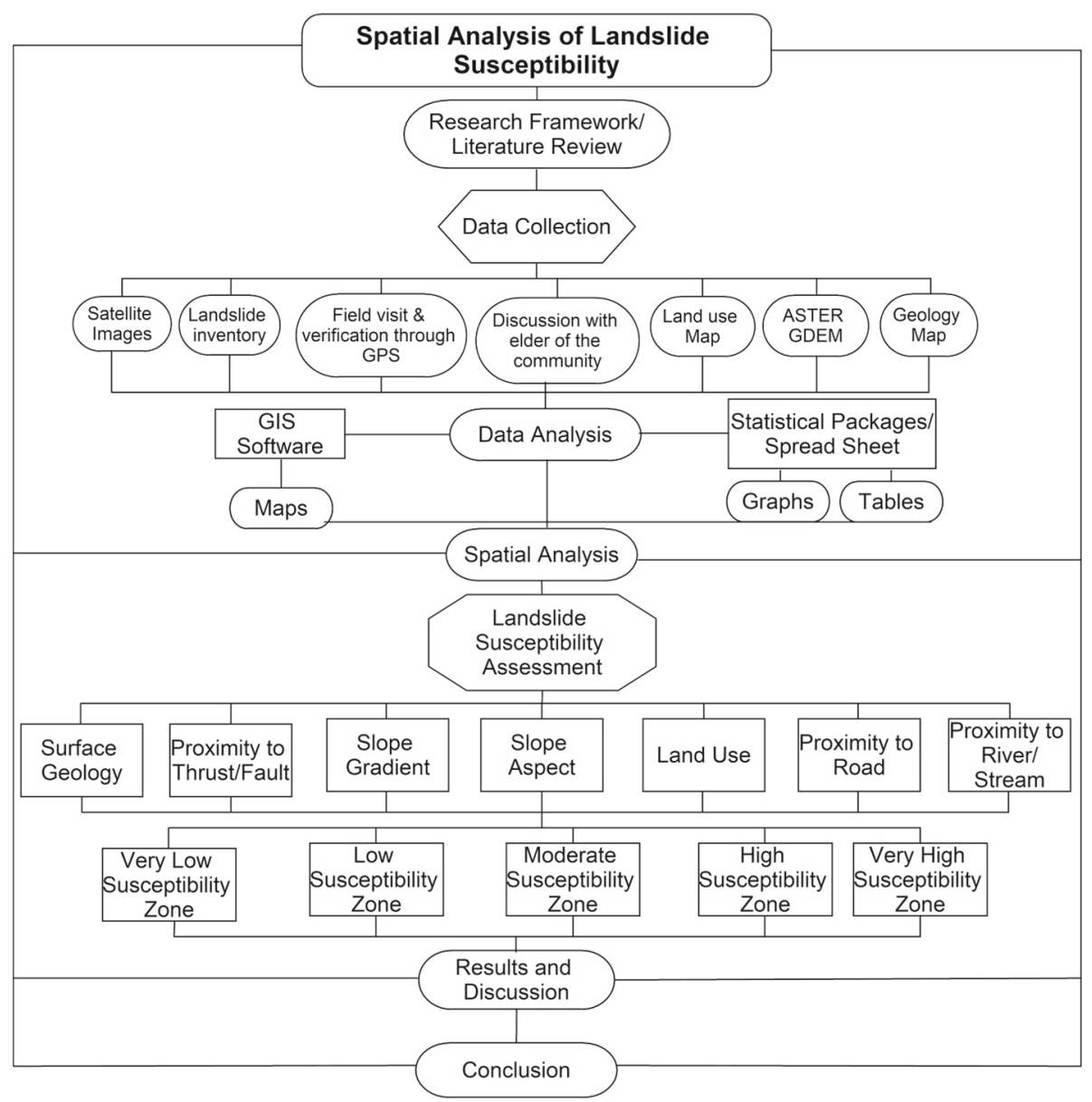

Figure 2. Research process. 
are readily available. SSFR method demarcates clear cut boundaries between different classes of susceptibility which is very important for intervention by the government line agencies and to initiate developmental projects and devise mitigation strategies well in advance. The SSFR approach provides quick and effective feedback to planners prior to planning any sort of activity over the fragile slopes. In the HKH region, frequent landslide incidences are a typical hindrance in developmental work. Therefore, assessment of landslide susceptible area is need of the day to mainstream it in decision-making process and to minimise the risk of landslides. In order to reduce the increasing impact of landslides on human lives and other properties, spatio-statistical landslide susceptibility mapping has recently been made an integral part of landslide risk reduction strategies.

\section{The study area}

Shahpur valley is located in the Hindu Raj mountains which is an offshoot of eastern Hindu Kush mountain system (Dichter 1967). The height of these mountains decreases from north to south. Shahpur valley is spread over an area of about $259 \mathrm{~km}^{2}$ and stretches between latitude $34^{\circ} 52^{\prime} 31^{\prime \prime}$ $35^{\circ} 9^{\prime} 35^{\prime \prime} \mathrm{N}$ and longitude $72^{\circ} 40^{\prime} 10^{\prime \prime}-72^{\circ} 48^{\prime} 44^{\prime \prime} \mathrm{E}$ (figure 1). Climatically, Shahpur valley falls in the moist temperate zone and receives ample amount of rainfall in summer from monsoon, whereas in winter the higher altitudes receive snowfall (Rahman et al. 2017). The climate of the area remains mild to warm in summer and cold in winter.

The tectonics and geology of HKH region are marked by the collision of the Eurasian plate with Indo-Australian plate, initiated in the Cretaceous

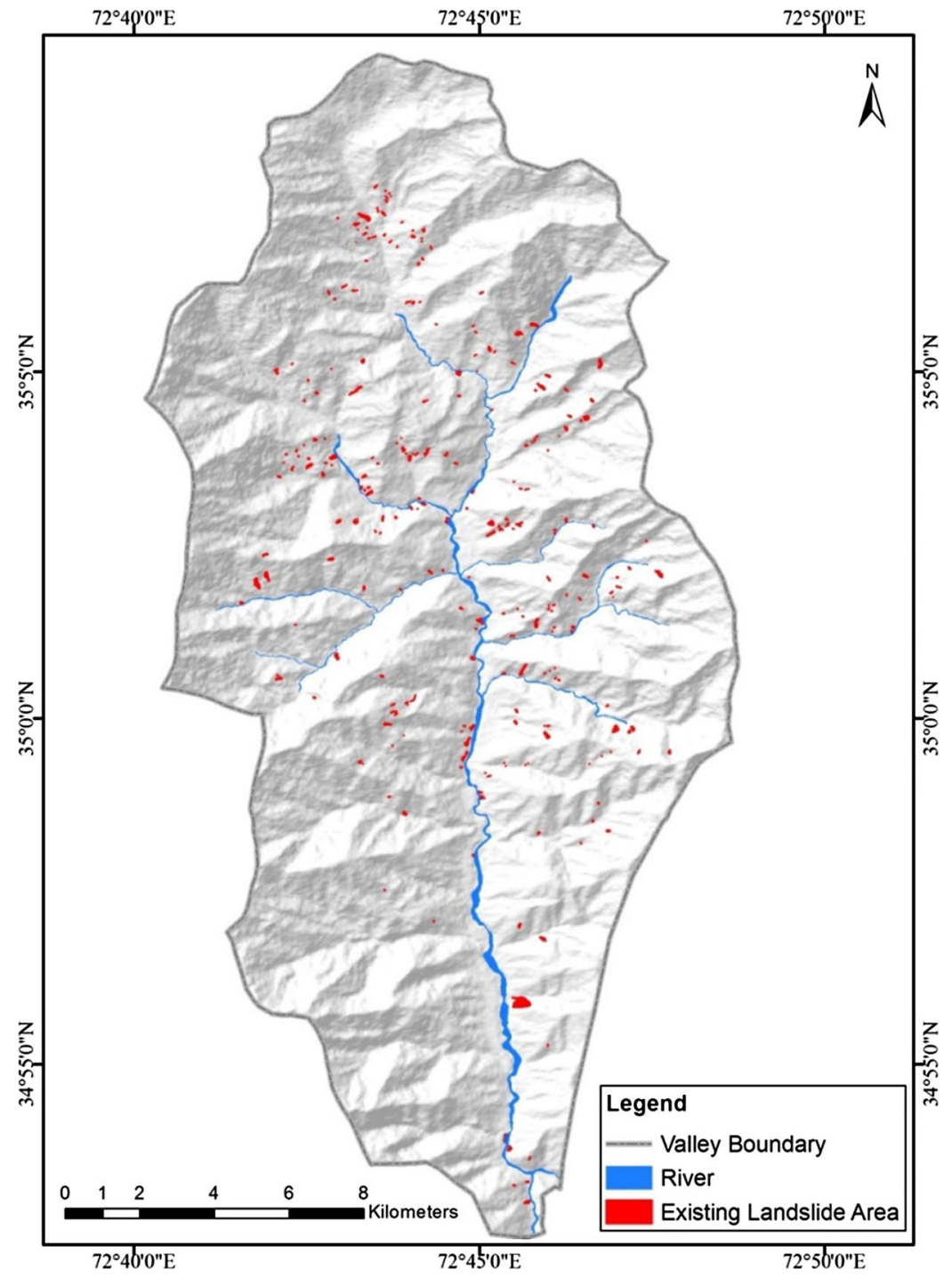

Figure 3. Shahpur valley, landslide inventory and distribution of past landslides. 
to Mio-Pliocene and still rising at a rate of 4-5 mm/yr (Jehan and Ahmad 2006). In Pakistan, the best exposure of geological phenomena and tectonics movement in the Hindu Kush region is located between Besham and Mingora (Kazmi et al. 1984). The physiography of Shahpur valley has great altitudinal variation that ranges from 880 to $4400 \mathrm{~m}$ above mean sea level (figure 1).
The slopes in the upper parts are steep and comparatively gentle in the lower reaches. The valley stretches northward from a town Karora and drains by a stream called as Khan Khwar. Geologically, the HKH region constitutes the youngest mountain system and almost every year, substantial amount of property damage and human loss is reported. These damages are expected to further

Table 1. Various data layers and their susceptibility score to landslide.

\begin{tabular}{|c|c|c|c|c|}
\hline Data layers & Classes & $\begin{array}{l}\text { Class } \\
\text { ratio }\end{array}$ & $\begin{array}{l}\text { Landslide } \\
\text { ratio }\end{array}$ & $\begin{array}{l}\text { Susceptibility } \\
\text { score }\end{array}$ \\
\hline \multirow[t]{9}{*}{ Surface geology } & Jijal Ultramafic & 0.014 & 0.000 & 0.000 \\
\hline & Jabrai Granite Gneiss & 0.192 & 0.102 & 0.534 \\
\hline & Karora Group & 0.194 & 0.126 & 0.652 \\
\hline & Manglaur Formation & 0.146 & 0.142 & 0.972 \\
\hline & Besham Group & 0.171 & 0.191 & 1.124 \\
\hline & Greenschist Melange & 0.064 & 0.074 & 1.163 \\
\hline & Alpurai Talc-mica-garnet schist & 0.091 & 0.129 & 1.427 \\
\hline & Alluvium & 0.112 & 0.196 & 1.758 \\
\hline & DSPGG & 0.017 & 0.036 & 2.142 \\
\hline \multirow[t]{3}{*}{ Proximity to thrust/fault } & $250 \mathrm{~m}$ & 0.287 & 0.402 & 1.397 \\
\hline & $500 \mathrm{~m}$ & 0.269 & 0.233 & 0.865 \\
\hline & $1000 \mathrm{~m}$ & 0.444 & 0.366 & 0.825 \\
\hline \multirow[t]{5}{*}{ Slope gradient } & $0-5^{\circ}$ & 0.026 & 0.013 & 0.487 \\
\hline & $6-15^{\circ}$ & 0.101 & 0.060 & 0.593 \\
\hline & $16-30^{\circ}$ & 0.258 & 0.257 & 0.996 \\
\hline & $31-45^{\circ}$ & 0.527 & 0.602 & 1.141 \\
\hline & $46^{\circ}$ and above & 0.088 & 0.069 & 0.787 \\
\hline \multirow[t]{9}{*}{ Slope aspect } & Flat & 0.000 & 0.000 & 0.000 \\
\hline & Northeast & 0.110 & 0.066 & 0.605 \\
\hline & North & 0.083 & 0.061 & 0.742 \\
\hline & Southeast & 0.153 & 0.114 & 0.749 \\
\hline & Southwest & 0.138 & 0.119 & 0.865 \\
\hline & West & 0.122 & 0.111 & 0.909 \\
\hline & East & 0.150 & 0.176 & 1.176 \\
\hline & Northwest & 0.103 & 0.132 & 1.286 \\
\hline & South & 0.142 & 0.219 & 1.546 \\
\hline \multirow[t]{6}{*}{ Land use/land cover type } & Glacier and snow & 0.056 & 0.000 & 0.000 \\
\hline & Built-up area & 0.014 & 0.006 & 0.404 \\
\hline & Forest & 0.415 & 0.354 & 0.853 \\
\hline & Range land & 0.330 & 0.337 & 1.021 \\
\hline & Agriculture land & 0.163 & 0.267 & 1.639 \\
\hline & Riverbed & 0.021 & 0.036 & 1.723 \\
\hline \multirow[t]{4}{*}{ Proximity to road } & $0-100 \mathrm{~m}$ & 0.049 & 0.087 & 1.797 \\
\hline & $101-200 \mathrm{~m}$ & 0.040 & 0.071 & 1.761 \\
\hline & 201-300 m & 0.036 & 0.079 & 2.187 \\
\hline & $301-400 \mathrm{~m}$ & 0.033 & 0.020 & 0.588 \\
\hline \multirow[t]{5}{*}{ Proximity to river/stream } & $0-50 \mathrm{~m}$ & 0.076 & 0.053 & 0.701 \\
\hline & $51-100 \mathrm{~m}$ & 0.064 & 0.168 & 2.629 \\
\hline & $101-200 \mathrm{~m}$ & 0.056 & 0.118 & 2.111 \\
\hline & $201-300 \mathrm{~m}$ & 0.028 & 0.047 & 1.670 \\
\hline & $301-400 \mathrm{~m}$ & 0.017 & 0.046 & 2.665 \\
\hline
\end{tabular}


increase in future due to heavy pressure on fragile slopes, infrastructural expansion, overgrazing, agricultural expansion, deforestation and climate change consequences.

\section{Materials and methods}

In the eastern Hindu Kush, Shahpur valley was selected for a detailed insight analysis to grasp the governing landslide causative factors, which frequently trigger the slope failure. Initially, an intensive review of the literature was conducted and reconnaissance field visits were made. The data from both primary and secondary data sources have been used to achieve the study objectives (figure 2). In this regard, the past landslide sites were identified and marked on SPOT $2.5 \mathrm{~m}$ satellite image of April 2013. A detailed field investigation was carried out to verify the landslide sites and the triggering factors. As a result, a detailed landslide inventory was developed. In the study area, focused group discussions (FGD) with local communities were conducted in order to get insight into major causative factors of landslide. Based on intensive field survey work, the landslide inventory and FGDs, seven major causative factors were identified and selected including geology, thrust/fault line, slope gradient, slope aspect, land use, proximity to road and river.

Data regarding landslide triggering factors were acquired. The surface geology and tectonics data were digitised from Geological map of North Pakistan (Searle and Khan 1996). The administrative boundaries and settlement shape files were prepared from topographic sheets (RF 1:50,000) obtained from a survey of Pakistan. Spatial features of road network were acquired from the office of Communication and Works Department, Peshawar. Land use/land cover map was prepared after applying supervised classification on SPOT satellite image using ArcGIS 10.2. ASTERGDEM $30 \mathrm{~m}$ was used for extracting slope angle, slope aspect and hydrology of the study area. Furthermore, a detailed field survey was conducted for ground verification and to validate the sites of already activated and potentially active landslide areas using a GPS receiver. In the present study, a semi-quantitative approach has been applied for calculating landslide failure rate for susceptibility zonation.
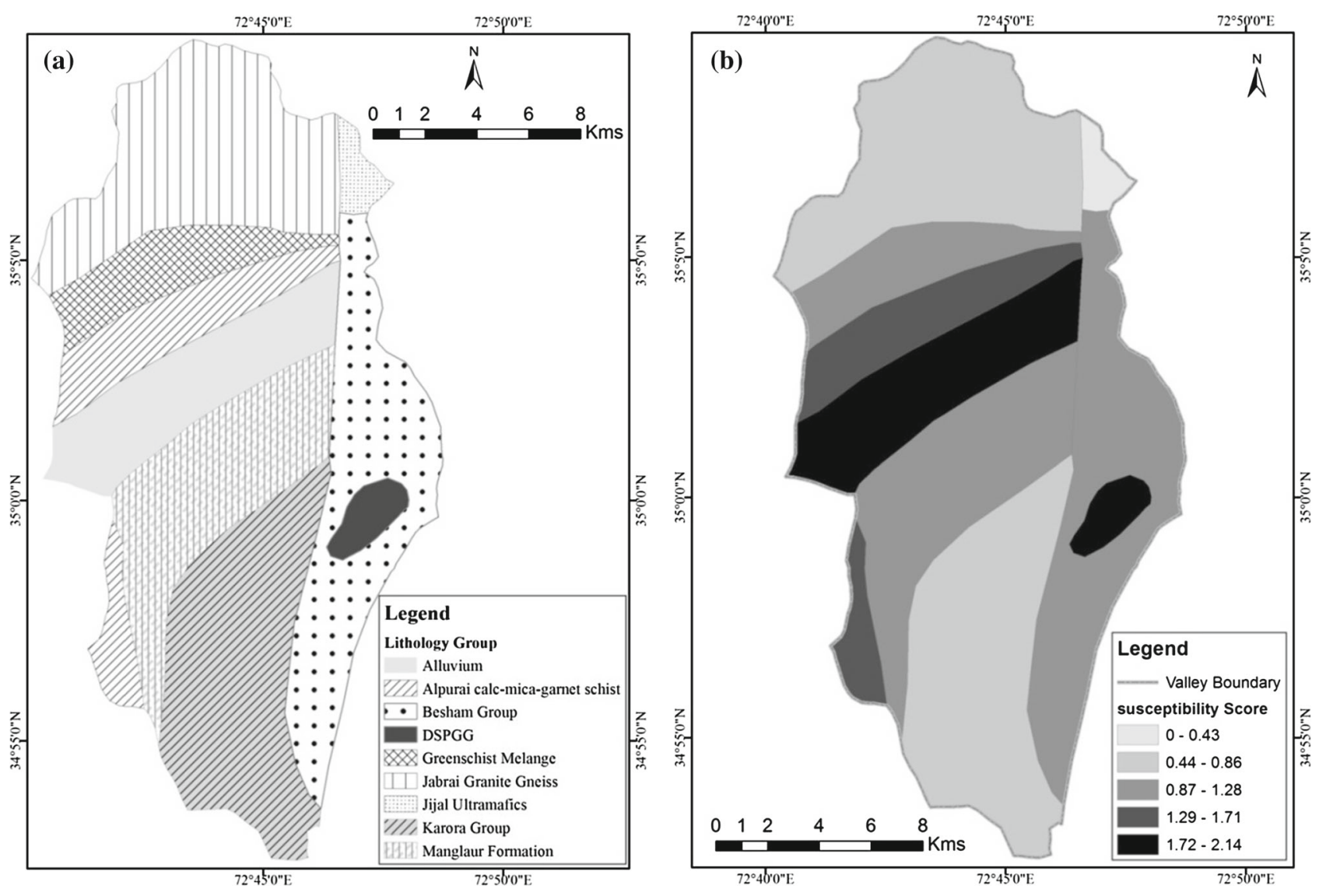

Figure 4. (a) Shahpur valley, surface geology and (b) geology susceptibility to landslide. 
GIS and remote sensing have been used for the preparation of spatial databases and landslide inventory for generating thematic layers of selected parameters required for the development of landslide susceptibility mapping. Failure rate analysis is a univariate statistical approach in which the importance of each factor or combined factors is individually analysed with respect to spatial distribution of existing landslides. The assumption in this method is that the factors which influenced the occurrence of landslides in the past are assumed to trigger new landslides in future. This approach was partially used by Dhakal et al. (1999) to assess the landslide influencing factors. To assess the influence of each class of a factor on landslide, a numerical score (susceptibility score) was computed in ArcGIS. In this study, the susceptibility score is calculated as

$$
\text { Susceptibility score }=\frac{R(L)}{R(A)}
$$

where $R(L)$ is a ratio of area under landslide in the specific class of a factor map to the total landslide area in the study region, whereas $R(A)$ is a ratio of area associated with a specific class to the total geographic area of the study region. The scores greater than 1 (one) suggest that this class of a particular factor map contributes to landslide occurrence, whereas a score less than 1 (one) specifies that this class of a particular factor map hinders landslides.

The thematic factor map is assumed to be an important determinant in landslide occurrence. After grouping the classes into sensible sets, the maps were rasterised for preparation of overlay analysis. GIS provides framework for integration of different landslide causal factors to produce map of LSZ. In this study, map of LSZ was classified according to their susceptibility based on integration of landslide causal factors. To minimise subjectivity, weights were assigned to each class within each causal factor map based on landslide susceptibility scores and the resultant maps were then overlaid using defined rules in ArcGIS, to produce a landslide susceptibility map. The resultant landslide susceptibility scores were then divided into five zones based on natural break
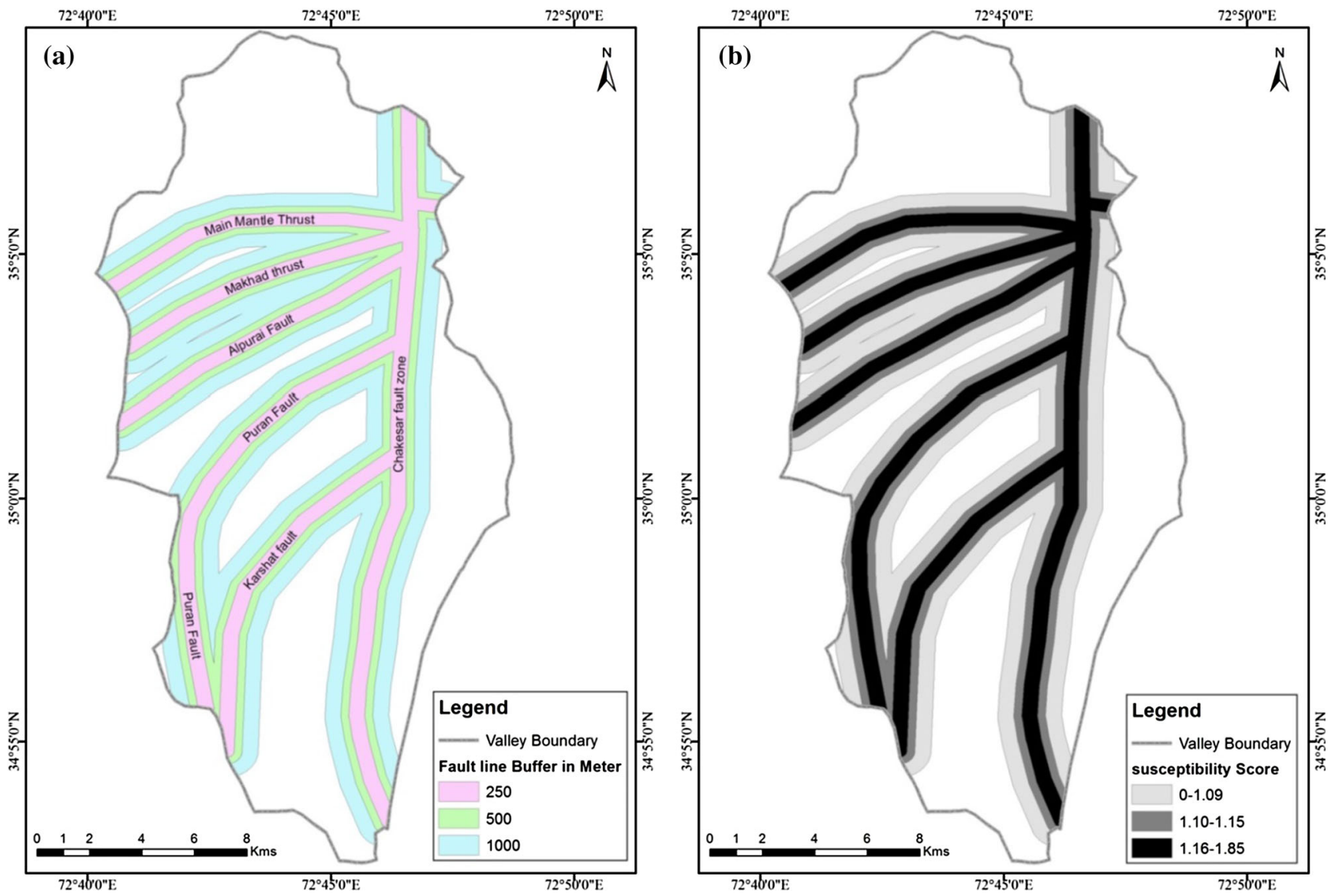

Figure 5. (a) Shahpur valley, thrust and fault line buffers and (b) landslide susceptibility score around thrust and fault line. 
representing very low, low, moderate, high and very high landslide susceptibility classes and finally, the LSZ map was validated at high confidence level.

\section{Analysis, results and discussions}

\subsection{Landslide inventory}

The preparation of an inventory map showing the spatial distribution of landslides is a preliminary step for a reliable LSZ. It is difficult to study and survey every landslide on the ground. Therefore, in this study, about 300 landslides were interpreted and mapped on SPOT satellite image (figure 3). Landslides were identified by spotting disturbed or absent vegetation cover and digitised in GIS, directly. However, the re-vegetated slopes may also represent landslide scars. To remove uncertainty in image interpretation, periodic field visits were conducted for accuracy. These landslides were then rasterised to calculate the area of landslide falling in different classes of each factor map for calculation of the landslide susceptibility score.

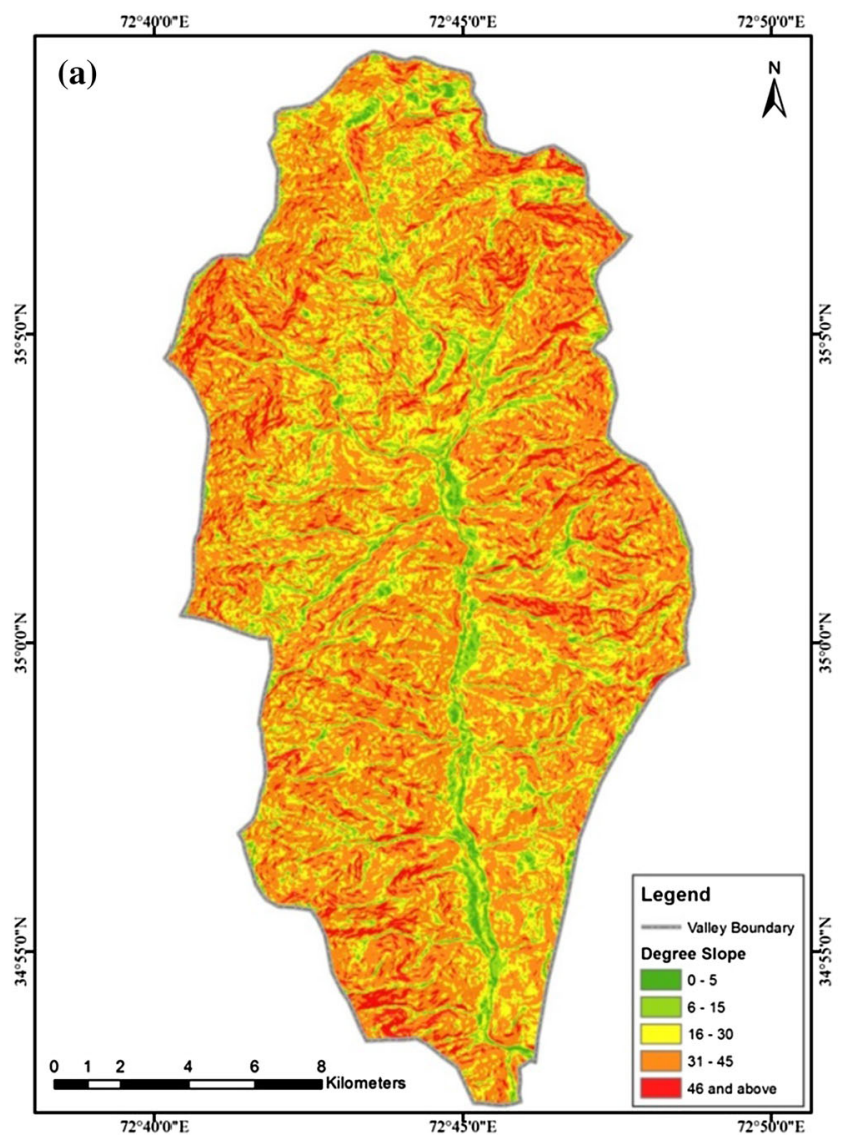

\subsection{Surface geology}

In Shahpur valley, landslide susceptibility has a close relationship with surface geological formation and rock types. Table 1 and figure 4(b) reveal the SSFR with respect to surface geology and susceptibility score under each class. As a result, the susceptibility score for each class was computed for entire Shahpur valley and displayed in figure 4(b). The highest susceptibility score was found in the Darwaza Sar Potassic Granite Gneiss (DSPGG), which is 2.14 and alluvium has the second highest susceptibility score (see figure $4 \mathrm{~b}$ ). The area under DSPGG was found in a small patch to have medium- to coarsegrained intrusive igneous rocks. In addition to its lithological composition, it was found that DSPGG area is also located on the edge of a major tectonic structure, the Chakesar fault zone (figure 4a). Therefore, it has a high susceptibility score. In Shahpur valley, the lithological component of alluvium belongs to the quaternary era and is mainly composed of clay, silt, pebbles, cobbles and boulders accumulated through fluvial processes mainly by Indus River and its tributaries

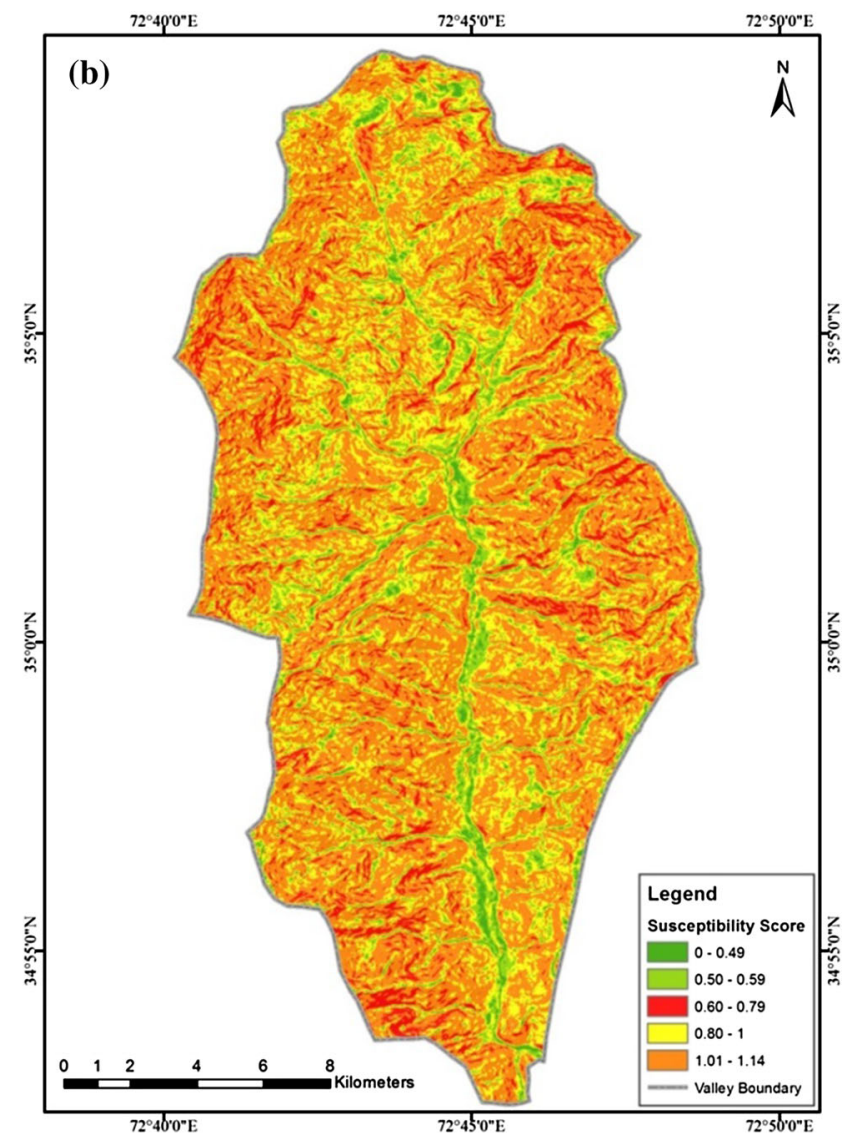

Figure 6. (a) Shahpur valley, slope gradient and (b) slope gradient and landslide susceptibility score. 
(Baig 1990). Alluvium consists of loose and unconsolidated material, where the extent of erosion and mass-movement is comparatively active and hence recorded second highest susceptibility score (table 1 and figure 4b). However, Jijal Ultramafics lies in a small area in the northeastern part of the valley, where no landslide activity is recorded in the past and hence the lowest susceptibility score was found. The second lowest susceptibility score was found in Karora Group with 0.65 followed by Jabrai Granite Gneiss with susceptibility score of 0.53.

\subsection{Proximity to thrust/fault}

In Shahpur valley, there is a complex tectonic setup, which is another contributing factor for slope failure processes. The thrust and fault line map has been produced from the geological map of Besham area after Baig (1990). The Main Mantle Thrust (MMT) and Makhad Thrust (MT) were found passing through the study area (figure 5a). Alpurai fault, Puran fault, Karshut fault and Chakesar fault lines also pass through the Shahpur valley and it has profound impact on slope failure. Applying the SSFR technique on the thrust and fault lines, multiple buffers of 250, 500 and $1000 \mathrm{~m}$ were generated in GIS environment. The aim of such buffer was to find out the impact of proximity to thrust and fault line on landsliding.

The analysis reveals that the highest susceptibility score was found in $250 \mathrm{~m}$ buffer that was 1.85 , whereas medium susceptibility was found around $500 \mathrm{~m}$ buffer and the lowest nearby $1000 \mathrm{~m}$ buffer, with a susceptibility score of 1.15 and 1.09 , respectively (table 1 and figure 5b). It was found from the analysis that these tectonic structures have profound impact on landslide susceptibility.

\subsection{Slope gradient}

The behaviour of landsliding has close association with the slope gradient (Wan et al. 2010). Since long, it has been recognised as a controlling factor in slope failure (Kamp et al. 2010; Rahman et al. 2011). Slope gradient is directly proportional to slope instability and similarly landslide
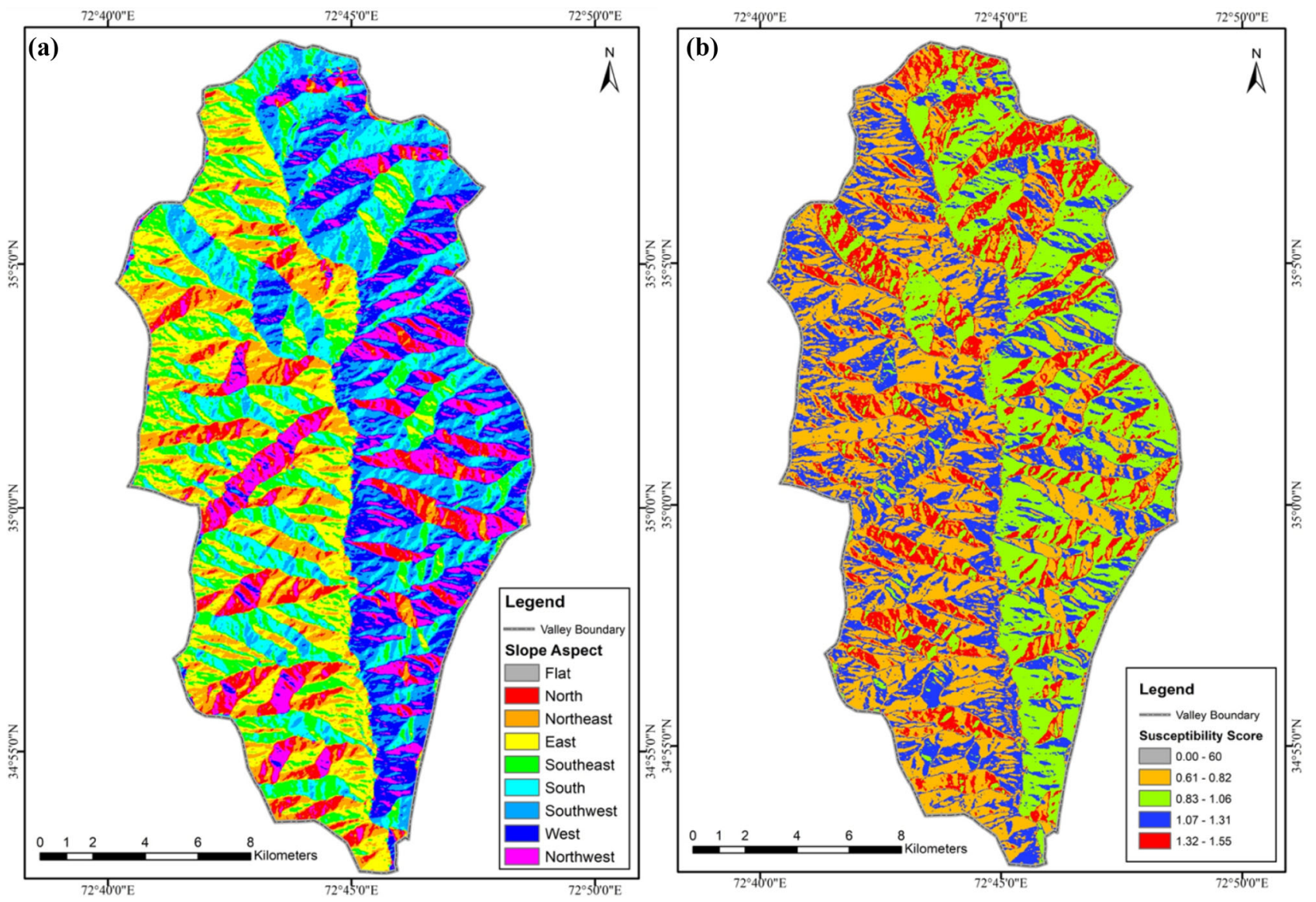

Figure 7. (a) Shahpur valley, slope aspect and (b) slope aspect and landslide susceptibility score. 
density increases with increase in slope gradient (Rahman et al. 2017). During field survey, it was found that there has been a high concentration of landslide events along the streams and roads, where there is an abrupt change in slope gradient.

The area under each slope class and activated landslides in that particular class with respect to susceptibility score has been discerned in table 1 . The slope up to $5^{\circ}$ is flat and holding relatively low landslide susceptibility scores. The analysis reveals that for the $6-45^{\circ}$ slopes, as the slope gradient increases, the rate of landslide occurrence also escalates. The landslide susceptibility score was also found relatively low at class $>45^{\circ}$ slope. To find out the root cause of low susceptibility score at high slope gradient, this region was studied in relation to other parameters such as land use/land cover and infrastructure. It was found that the anthropogenic activities over more than $45^{\circ}$ slope are very limited and the area is mostly covered by forest. The spatio-statistical analysis reveals that the highest landslide failure rate has been found in class $31-45^{\circ}$ slopes (table 1 and figure 6b).

\subsection{Slope aspect}

The literature reveals that slope aspect does not have direct impact on landslide activation, but it indirectly stimulates landslide. It largely depends on duration and intensity of sunlight falling on the slope as well as intensity and the amount of precipitation it receives along with moisture retaining potential have strong correlation (Dai et al. 2002; Kouli et al. 2010). It has been explored that rain-induced landsliding is a common phenomenon in the Himalayas-Hindu Kush region. The slope aspect of Shahpur valley is shown in figure 7 (a) with flat, north, northeast, east, southeast, south, southwest, west and northwest facing slopes. In the entire Hindu Kush region, the south facing slopes have high sunlight exposure and receive maximum precipitation both during winter and summer monsoon.

In addition to precipitation and forest cover, thermal expansion and contraction is also one of the active physical phenomena on the slopes exposed to the sunlight. Therefore, the south facing slopes have a high tendency to slope failure
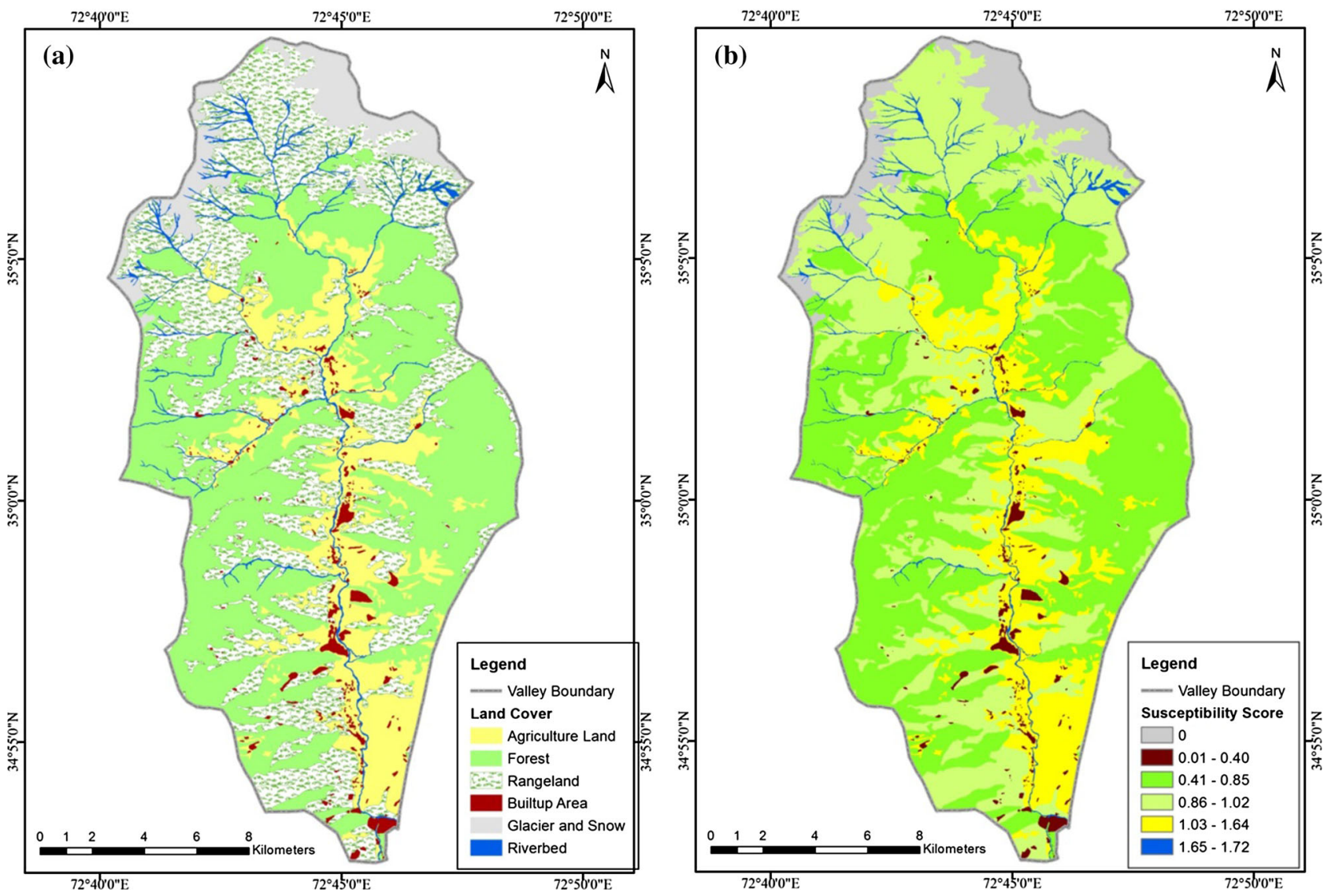

Figure 8. (a) Shahpur valley, land use/land cover and (b) land use/land cover and landslide susceptibility score. 
and as a result recorded the highest landslide susceptibility score of 1.55 (table 1 and figure $7 \mathrm{~b}$ ). In some cases, the reason for high susceptibility is the indirect impact of aspects with geological characteristics such as slope parallel bedding-planes and/or dominating joint systems. The second highest susceptibility score was found on the northwest facing slopes, because such slopes receive high rain and snow during winter. Likewise, the east facing slopes receive high rainfall from monsoon, and has the third highest susceptibility score. The flat and northeast facing slopes fall in one class with the lowest susceptibility $0.00-0.60$. North and southeast facing sloped were found in class 0.610.82 , which also have a low susceptibility score. The south and northwest slopes have a score of 1.32-1.55, which indicate high susceptibility. The analysis of slope aspect reveals that difference in landslide failure rate has certain relationship with exposure to sunlight and variation in intensity and amount of precipitation.

\subsection{Land use}

Vegetation cover is an important factor determining the process of soil erosion and slope failure,

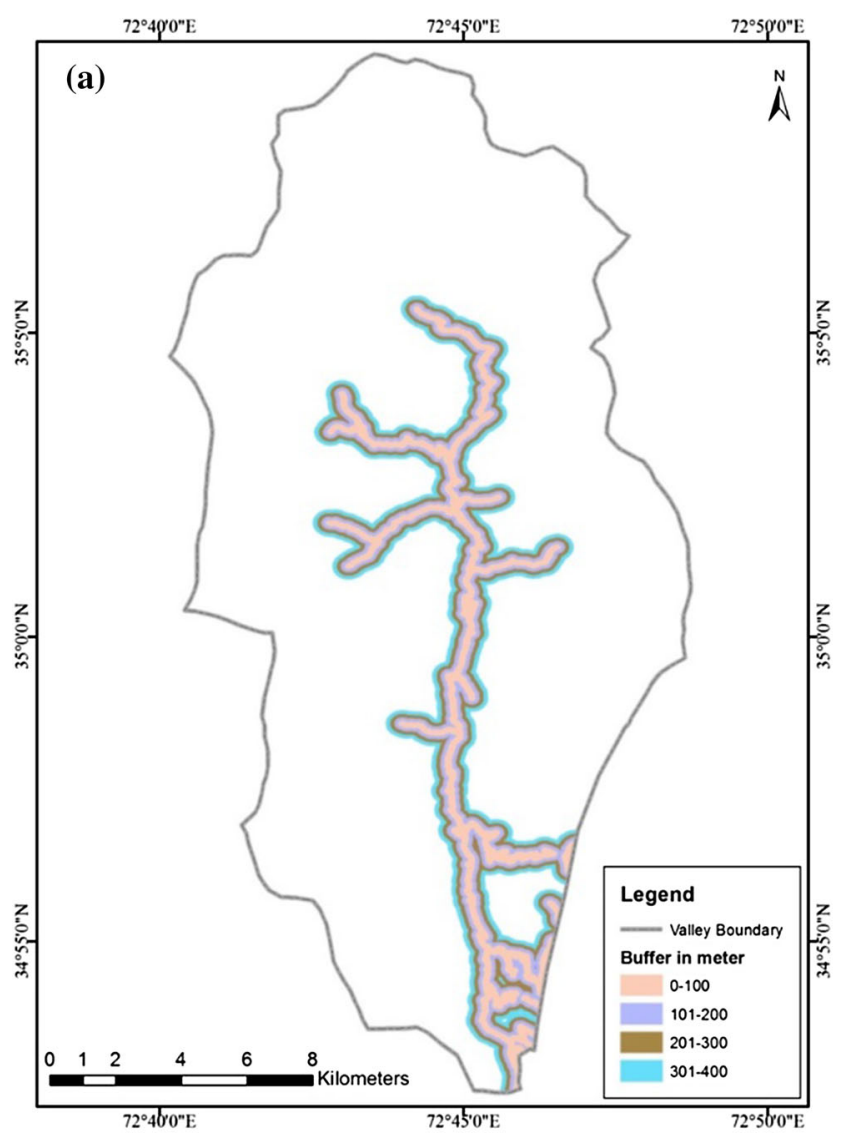

where the roots bind the soil and keep the slope stable. However, the unconsolidated material with bare slopes has more exposure to erosional activities and leads to slope instability. In the study region, land use/land cover has been categorised into agricultural land, forest cover, rangeland, built-up area, glacier and snow cover and riverbed (table 1 and figure 8a).

The highest susceptibility score was found in class riverbed mainly due to active lateral erosion and exposure of nearby slopes to landslide (figure $8 \mathrm{~b}$ ). The analysis further reveals that the second highest susceptibility score was found in agriculture land use class, where agriculture is mostly practiced over the terraced field. It has been observed during field survey that agricultural fields are prepared on slopes in the form of terraces, which have sharp edges with a little support of loose material as retaining wall. The normal drainage pattern over the slopes gets worse in rainy season, when excessive amount of runoff passes through these terrace farmland and triggers landslides. It was found from the analysis that in Shahpur valley the role of human intervention in the form of terraced fields over these fragile slopes is one of the main determining factors in

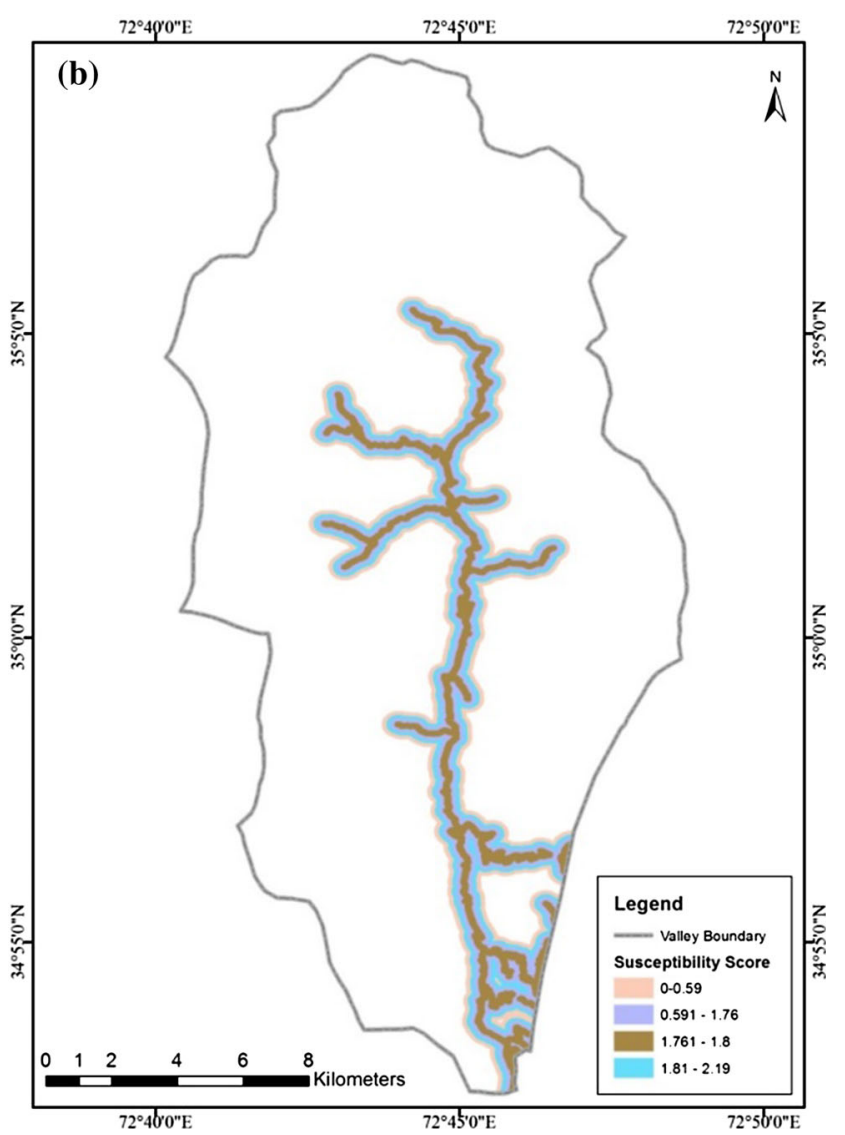

Figure 9. (a) Shahpur valley, road buffers and (b) roads and landslide susceptibility score. 
landslide activation. However, the susceptibility score for rest of the land use/land cover classes was found to be relatively low.

\subsection{Proximity to road}

In mountain environment, the construction of road involves extensive excavations that disturb the fragile slope and accelerate the process of slope failure (Promper et al. 2014). In this study, proximity to road was used as a parameter for determining failure rate and computing its susceptibility. Using spatial features of road network, multiple ring buffers of $0-100,101-200,201-300$ and 301$400 \mathrm{~m}$ were applied to find out the impact of road proximity on landslides susceptibility (figure 9a). The analysis reveals that landslide susceptibility score was found to be high in the buffer area of 0-100 and 201-300 m (table 1 and figure 9b). Field survey reveals that it is mostly the slopes which were disturbed due to expansion and construction of new roads. The analysis further reveals that the lowest susceptibility score was found in 301-400 m buffer zone. It was found from the analysis that there is a close relationship of failure rate and landslide activation. As a consequence, a sharp decline in susceptibility score was found in buffer zone $>300 \mathrm{~m}$ (table 1$)$.

\subsection{Proximity to river/stream}

Streams of the first order were buffered at a distance of $0-50 \mathrm{~m}$, second order at $0-50$ and $51-100$ $\mathrm{m}$, streams of third order were multiple buffered at a distance of $0-50,51-100$ and $101-200 \mathrm{~m}$. The streams of fourth order were also multiple buffered at a distance of $0-100,101-200$ and $201-300 \mathrm{~m}$, while the streams of fifth order were buffered at a distance of 0-100, 101-200, 201-300 and 301-400 $\mathrm{m}$ (figure 10a).

The lowest susceptibility score was found in buffer zone $0-50 \mathrm{~m}$. The buffer area around 0-50 $\mathrm{m}$ is the first-order and second-order streams. The first-order streams are small and narrow and do not have much effect on landsliding. The analysis further reveals that the highest landslide susceptibility score was found in the buffer of 301-400 m (figure 10b). This range of buffer was exclusively
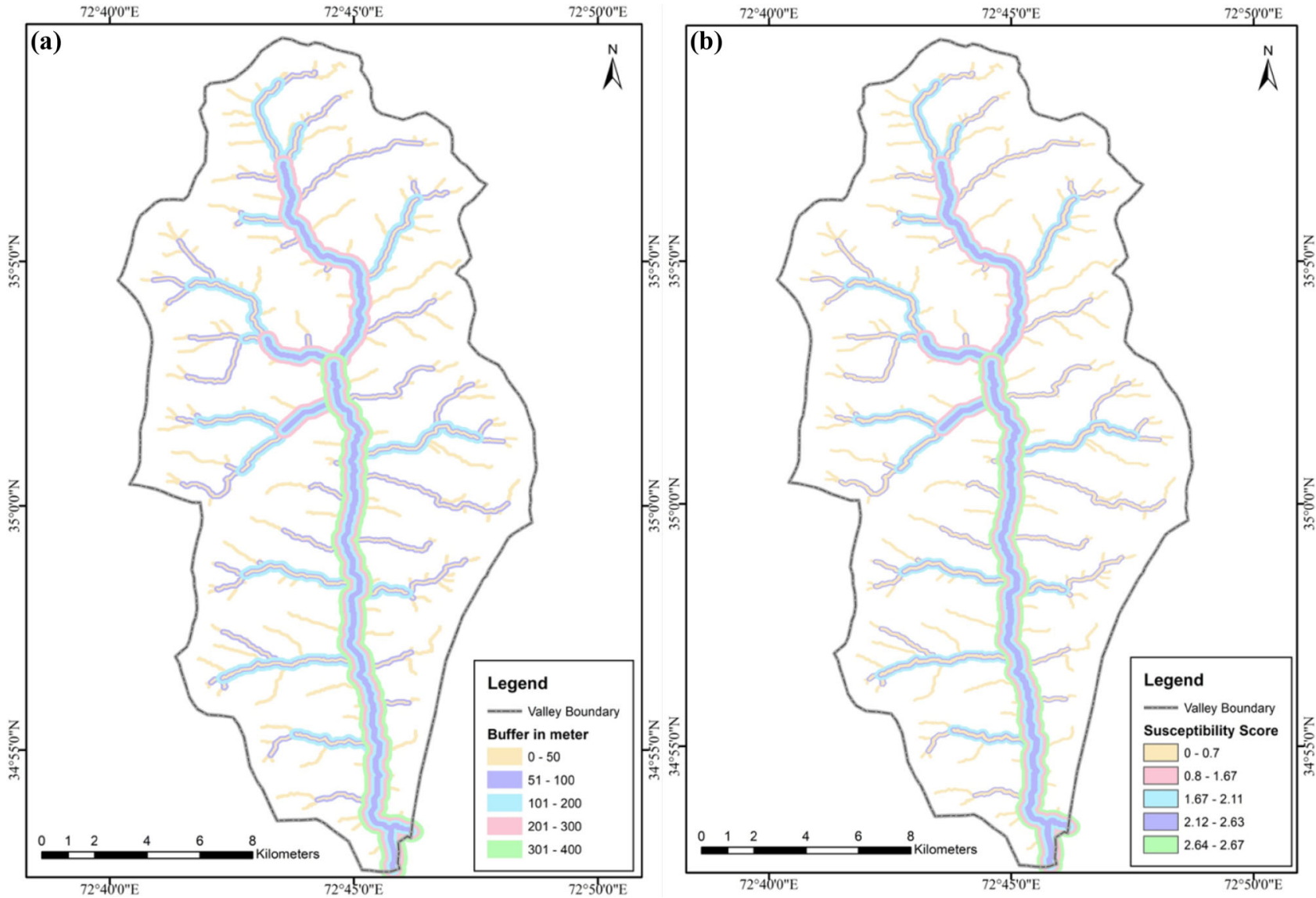

Figure 10. (a) Shahpur valley, river/stream buffer and (b) river/stream and landslide susceptibility score. 
applied on fourth- and fifth-order streams, which are the main streams flowing through the study area with high runoff during summer monsoon. They flow through mountainous area; therefore, they have high lateral erosion and encourage landsliding. The second highest landslide susceptibility score was found in class around $51-100 \mathrm{~m}$ buffer.

\subsection{Landslide susceptibility zonation}

LSZ is a process which divides the area into different classes according to their susceptibility scores on certain parameters. In Shahpur valley, a technique of failure rate analysis was applied with a univariate statistical approach. Seven major causative factors i.e., geology, thrust/fault line, slope gradient, slope aspect, land use, proximity to road and river were analysed with respect to already activated landslides using SFFR and the susceptibility score for each class of these causative factors were calculated. The entire causative factor maps were then combined based on their respective susceptibility score using overlay analysis in ArcGIS and the resulting LSZ map was produced. The LSZ map has been categorised into five zones of very low, low, moderate, high and very high landslide susceptibility based on failure rate score (figure 11).

It was found from the analysis that Shahpur valley has a high potential for landslide susceptibility. Out of total $259 \mathrm{~km}^{2}$ of Shahpur valley, the share of high landslide susceptibility zone is $38.49 \mathrm{~km}^{2}$ making $14.9 \%$ of the total geographical area (table 2 and figure 11). The moderate landslide susceptibility zone is $161.78 \mathrm{~km}^{2}(62.5 \%)$ and very high landslide susceptibility zone is $2.65 \mathrm{~km}^{2}$ of the total area. The very high landslide susceptibility zone lies mostly in the central part of the valley. The analysis further reveals that landslide is a common

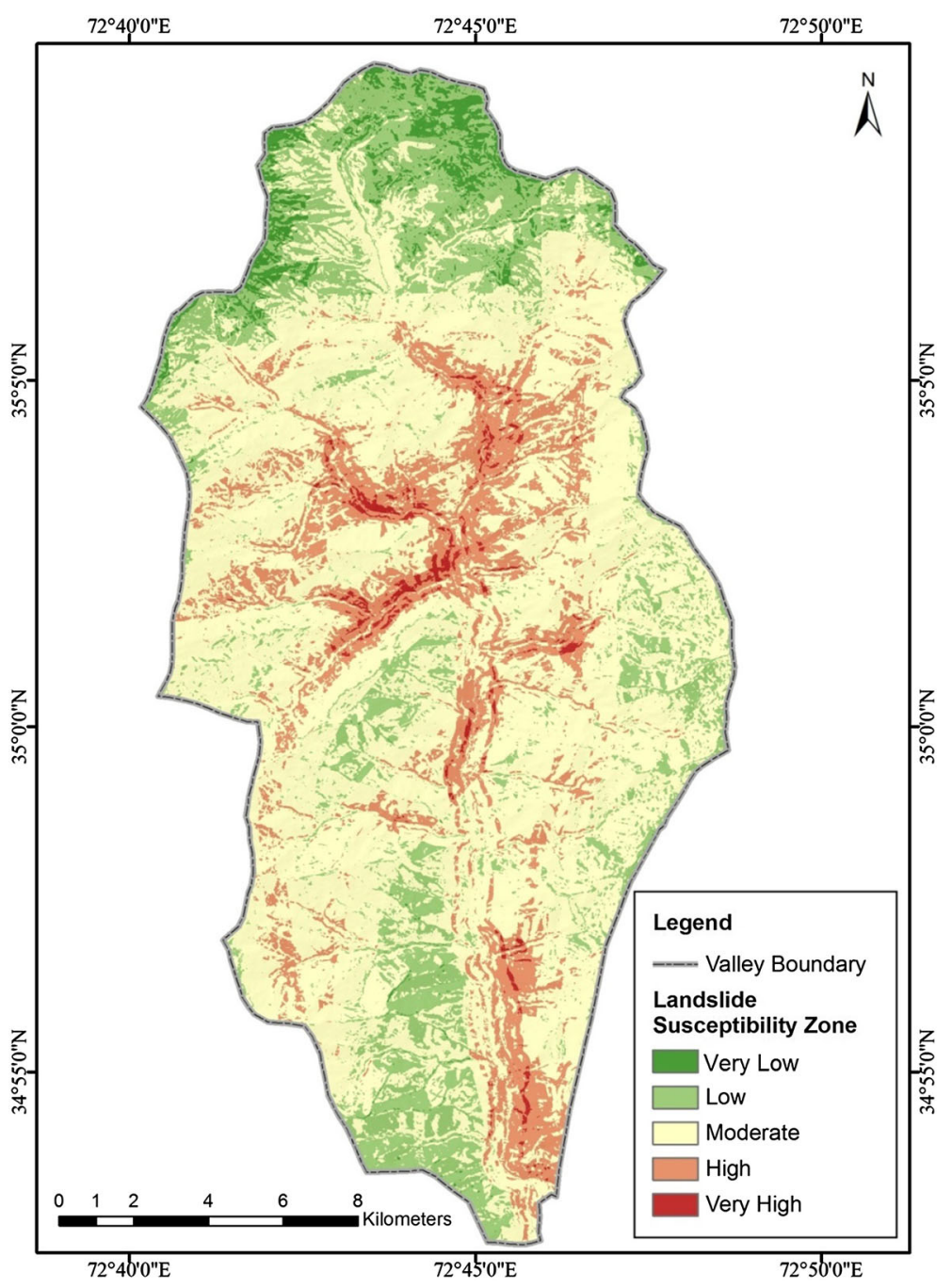

Figure 11. Shahpur valley, landslide susceptibility zonation. 
Table 2. Shahpur valley, landslide susceptibility zone and their occupied area.

\begin{tabular}{lrc}
\hline Landslide hazard zonation & Area $\left(\mathrm{km}^{2}\right)$ & Percentage \\
\hline Very low & 3.58 & 1.4 \\
Low & 51.94 & 20 \\
Moderate & 161.78 & 62.5 \\
High & 38.49 & 14.9 \\
Very high & 2.65 & 1.2 \\
\hline
\end{tabular}

problem and occurs almost in all parts of Shahpur valley. In 2010 at village Olandar where a devastating landslide occurred and caused 60 deaths and heavy property loss also falls in very high landslide susceptibility zone. The analysis indicates that high to very high landslide susceptibility zone lies at the confluence of three major streams, which accelerates landsliding due to undercutting process (see figure 10b). While taking geological perspectives, the high to very high susceptibility zone falls in the region of alluvium and bears high tendency towards landslide (see figure 4a). Similarly, the tectonic structures of MMT, MT and PF also fall in the high to very high susceptibility zone (see figure 5a). The contribution of anthropogenic factors in high to very high landslide susceptibility zone is of key concern and mainly includes areas of high road density and terraced agriculture over the fragile slopes.

\subsection{Validation of landslide susceptibility zonation}

Validation of LSZ was applied to verify and test the research hypothesis that the occurrence of landslides has a close relationship with the selected failure factors. The accuracy assessment of LSZ map was produced following SSFR analysis and the results were compared with the area of past landslides in the area. Finally, the area of each landslide susceptibility zone and landslides area in that particular zone were calculated. The percentage of landslide area in that particular class was calculated using the equation

\section{Validation of LSZ}

$$
\begin{aligned}
= & \frac{\text { Landslide area in a particular landslide zone }}{\text { Total area of that particular landslide zone }} \\
& \times 100 .
\end{aligned}
$$

Based on the assumption, it was hypothesised that the proportion of landslide area will be more in high and very high landslide susceptibility zones. Figure 12 further illustrates that out of total activated landslide area, there has been no landslide in very low susceptibility zone, whereas the percentage of landslide area in very high and high susceptibility zones is comparatively more.

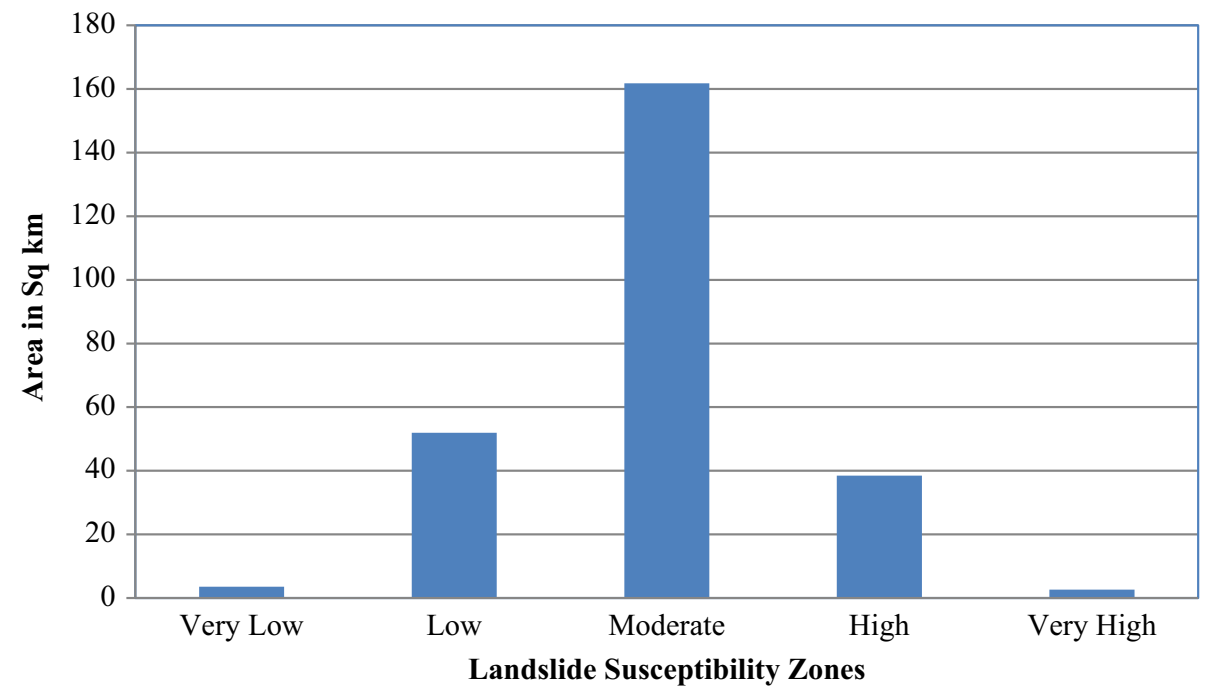

Figure 12. Shahpur valley, validation of landslide susceptibility zones. 


\section{Conclusion}

The topography and fragile geology of the HKH region coupled with climatic conditions and human intervening factors have made it more susceptible to landslide hazard. The analysis revealed that Shahpur valley is the worst landslide affected area. Here, landslides are mostly triggered either by intense rainfall, seismic activity and or humaninduced factors. However, the prominent role of human interventions cannot be ignored, where rapid growth of population, deforestation and infrastructural development over the unstable slopes has further aggravated the recurrence of landslides.

In the study area, landslides of various sizes were identified and marked on SPOT $2.5 \mathrm{~m}$ scene. In the present study, a univariate SSFR approach was applied to analyse the impact of geology, tectonic structure, land use/land cover, slope aspect, slope gradient, river and roads on landslide. It was found that the geology of DSPGG and alluvium has the highest tendency for landslide and secured high susceptibility scores. Both geological units (DSPGG and alluvium) consist of unconsolidated material and thus have high susceptibility to landslide occurrence. It was also found that tectonic structures have a profound impact on landslide susceptibility and the number of landslides was found to be high near the tectonic structure.

While analysing the impact of slope gradient on landslide susceptibility, it was found that 31$45^{\circ}$ slopes have high susceptibility as compared to above $45^{\circ}$ slope gradient. It was found that $31-45^{\circ}$ slopes were largely disturbed by human intervention, while the steep slopes were mostly found under tree cover in the lower reaches of Shahpur valley. Slope aspect does not have a direct impact on landslide susceptibility, but it has a close relationship with sunlight exposure and rainfall occurrences. It was found that the south facing slopes have high landslide susceptibility. It is mainly because the southern slopes have more sunlight exposure and rainfall and therefore, have high susceptibility towards the activation of landslide.

In the study area, human activities and infrastructural developments are the main cause of disturbing the natural slopes and, therefore, roads, housing and agricultural land were found to be the main contributors in making a slope susceptible to landslide. The impact of river bank erosion has also joined hands in escalating the landslide susceptibility. In LSZ, all the selected failure rate factors were combined through weighted overlay and LSZ map was produced. In Shahpur valley, out of total $259 \mathrm{~km}^{2}$ area, $2.65 \mathrm{~km}^{2}$ was found under very high landslide susceptibility zone, whereas $38.49 \mathrm{~km}^{2}$ was in high susceptibility zone, which is $14.9 \%$ of the total geographic area.

The analysis revealed that in Shahpur valley extensive area is susceptible to landslides. Therefore, in this paper, an attempt has been made to analyse the landslide susceptibility on the basis of selected potential triggering parameters. As a result, the landslide susceptibility zones have been developed and the same has been validated at high confidence level. The developed landslide zonation map has been classified into five zones of very low, low, moderate, high and very high landslide susceptible zones for providing effective support to decision makers. In the study region, application of SSFR approach is a pioneering attempt in preparing landslide susceptible map and is very useful for the line agencies and related government organisations to consider its findings before implementation of any developmental project in the study area. This study also proposes that government should implement landslide risk reduction strategies for minimising its probable adverse consequences. The proposed spatio-statistical methodology is a mix method of qualitative and quantitative approach and convenient to apply on the entire Hindu Kush, Himalaya and Karakoram region. This will obviously help policymakers to implement landslide mitigation strategies in different LSZ and the results are equally very useful prior to the implementation of any infrastructure project.

\section{Acknowledgements}

This research would not have been possible without the technical support of our colleagues Mr Liaqat Ali Khan and Mr Alamsher Bacha. We thank them for giving valuable ideas and support in the application of GIS.

\section{References}

Akbar T A and Ha S R 2011 Landslide hazard zoning along Himalayan Kaghan valley of Pakistan - By integration of GPS, GIS, and remote sensing technology; Landslides 8(4) 527-540.

Allen S K, Cox S C and Owens I F 2011 Rock avalanches and other landslides in the central Southern Alps of New Zealand: A regional study considering possible climate change impacts; Landslides 8(1) 33-48. 
Ayalew L and Yamagishi H 2005 The application of GISbased logistic regression for landslide susceptibility mapping in the Kakuda-Yahiko Mountains, Central Japan; Geomorphology 65(1) 15-31.

Baig M S 1990 Structure and geochronology of PreHimalayan and Himalayan orogenic events in the Northwest Himalayan, Pakistan, with special reference to the Besham area; PhD Thesis, Oregon State University.

Conforti M, Pascale S, Robustelli G and Sdao F 2014 Evaluation of prediction capability of the artificial neural networks for mapping landslide susceptibility in the Turbolo river catchment (northern Calabria, Italy); Catena 113 $236-250$

Dai F, Lee C and Ngai Y Y 2002 Landslide risk assessment and management: An overview; Eng. Geol. 64(1) 65-87.

Dhakal A S, Amada T and Aniya M 1999 Landslide hazard mapping and the application of GIS in the Kulekhani watershed, Nepal; Mountain Res. Develop. 19(1) 3-16.

Dichter D 1967 The North-West Frontier of West Pakistan: A Study in Regional Geography; Clarendon Press, Oxford.

Farooq M S 1997 Geotechnical study of landslide problems along the Murree, Muzaffarabad Road, Pakistan; PhD Thesis, University of Punjab.

Hussin H Y, Zumpano V, Reichenbach P, Sterlacchini S, Micu M, van Westen C and Bălteanu D 2016 Different landslide sampling strategies in a grid-based bi-variate statistical susceptibility model; Geomorphology 253 508523, https://doi.org/10.1016/j.geomorph.2015.10.030.

Jehan N and Ahmad I 2006 Petrochemistry of asbestos bearing rocks from Skhakot-Qila ultramafic complex northern Pakistan; J. Health Stud. 39 75-83.

Kamp U, Owen L A, Growley B J and Khattak G A 2010 Back analysis of landslide susceptibility zonation mapping for the 2005 Kashmir earthquake: An assessment of the reliability of susceptibility zoning maps; Nat. Hazards 54(1) 1-25.

Kanungo D, Arora M, Sarkar S and Gupta R 2009 Landslide susceptibility zonation (LSZ) mapping - A review; J. S. Asian Stud. 2(1) 81-105.

Kazmi A, Lawrence R, Dawood H, Snee L and Hussain S 1984 Geology of the Indus suture zone in the MingoraShangla area of Swat; Geol. Bull. 17 127-144.

Kouli M, Loupasakis C, Soupios P and Vallianatos F 2010 Landslide hazard zonation in high risk areas of Rethymno prefecture, Crete Island, Greece; Nat. Hazards 52(3) 599621.

Mirnazari J and Ahmad B B 2013 The generation of landslide susceptibility map using physical (experimental) method: A case study in Cheshme Kabud district, Iran; Int. J. Eng. Res. Technol. 2(2) 1-25.
Nandi A and Shakoor A 2010 A GIS-based landslide susceptibility evaluation using bivariate and multivariate statistical analyses; Eng. Geol. 110(1) 11-20.

Pareek N, Sharma M L and Arora M K 2010 Impact of seismic factors on landslide susceptibility zonation: A case study in part of Indian Himalayas; Landslides 7(2) 191201.

Promper C, Puissant A, Malet J-P and Glade T 2014 Analysis of land cover changes in the past and the future as contribution to landslide risk scenarios; Appl. Geogr. 53 11-19.

Rahman A and Shaw R 2014 Floods in the Hindu Kush Region: Causes and Socio-Economic Aspects. Mountain Hazards and Disaster Risk Reduction; Springer, Tokyo, pp. 33-52.

Rahman A, Khan A N, Collins A E and Qazi F 2011 Causes and extent of environmental impacts of landslide hazard in the Himalayan region: A case study of Murree, Pakistan; Nat. Hazards 57(2) 413-434.

Rahman A, Khan A N and Collins A E 2014 Analysis of landslide causes and associated damages in the Kashmir Himalayas of Pakistan; Nat. Hazards 71(1) 803-821.

Rahman G, Rahman A, Samiullah and Collins A 2017 Geospatial analysis of landslide susceptibility and zonation in shahpur valley, eastern Hindu Kush using frequency ratio model; Proc. Pak. Acad. Sci. 54(3) 149-163.

Searle M P and Khan M A 1996 Geological Map of North Pakistan and Adjacent Areas of Northern Ladakh and Western Tibet, Scale 1:650,000; Oxford University, Oxford.

Sengupta A, Gupta S and Anbarasu K 2010 Rainfall thresholds for the initiation of landslide at Lanta Khola in north Sikkim, India; Nat. Hazards 52(1) 31-42.

Sudmeier-Rieux K, Jaquet S, Derron M-H, Jaboyedoff M and Devkota S 2012 A case study of coping strategies and landslides in two villages of Central-Eastern Nepal; Appl. Geogr. 32(2) 680-690.

Van Westen C J, Castellanos E and Kuriakose S L 2008 Spatial data for landslide susceptibility, hazard, and vulnerability assessment: An overview; Eng. Geol. 102(3) $112-131$.

Van Westen C, Quan Luna B, Vargas Franco R, Malet J, Jaboyedoff M, Horton P and Kappes M 2010 Development of training materials on the use of geo-information for multi-hazard risk assessment in a mountainous environment; In: Paper presented at the Proceedings of the Mountain Risks International Conference, Firenze, Italy.

Wan S, Lei T and Chou T 2010 A novel data mining technique of analysis and classification for landslide problems; Nat. Hazards 52(1) 211. 